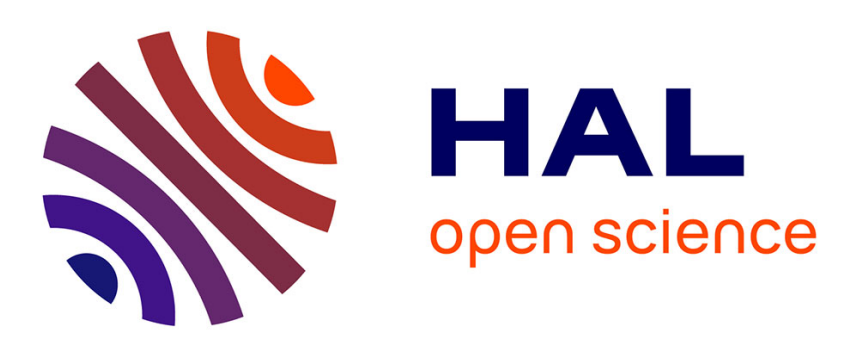

\title{
A new direction in design of bio-based flame retardants for poly(lactic acid)
}

F. Laoutid, Henri Vahabi, M. Shabanian, F. Aryanasab, P. Zarrintaj, M. R Saeb

\section{- To cite this version:}

F. Laoutid, Henri Vahabi, M. Shabanian, F. Aryanasab, P. Zarrintaj, et al.. A new direction in design of bio-based flame retardants for poly(lactic acid). Fire and Materials, 2018, 42 (8), pp.914-924. 10.1002/fam.2646 . hal-02303839

\section{HAL Id: hal-02303839 \\ https://hal.science/hal-02303839}

Submitted on 26 Nov 2020

HAL is a multi-disciplinary open access archive for the deposit and dissemination of scientific research documents, whether they are published or not. The documents may come from teaching and research institutions in France or abroad, or from public or private research centers.
L'archive ouverte pluridisciplinaire HAL, est destinée au dépôt et à la diffusion de documents scientifiques de niveau recherche, publiés ou non, émanant des établissements d'enseignement et de recherche français ou étrangers, des laboratoires publics ou privés. 


\title{
A New Direction in Design of Bio-based Flame Retardants for Poly(lactic acid)
}

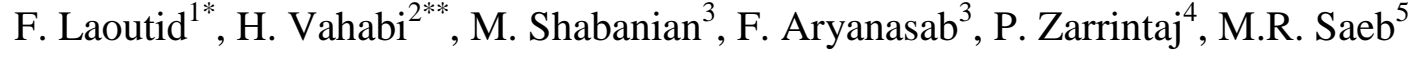 \\ ${ }^{1}$ Laboratory of Polymeric \& Composite Materials, Materia Nova Research Center, Place du Parc 23, B-7000 \\ Mons (Belgium) \\ ${ }^{2}$ Université de Lorraine, Laboratoire MOPS E.A. 4423, Metz F-57070, France \\ ${ }^{3}$ Faculty of Chemistry and Petrochemical Engineering, Standard Research Institute (SRI), P.O. Box: 31745 - \\ 139, Karaj, Iran \\ ${ }^{4}$ School of Chemical Engineering, College of Engineering, University of Tehran, P.O. Box: 11155-4563, Tehran, \\ Iran \\ ${ }^{5}$ Department of Resin and Additives, Institute for Color Science and Technology, P.O. Box 16765-654, Tehran, \\ Iran
}

\begin{abstract}
A novel bio-based nitrogen-and phosphorus-rich flame retardant (Phyt/PEI-TA) was synthesized and characterized by Fourier transform infrared (FTIR), Inductively Coupled Plasma (ICP) and thermogravimetric analysis (TGA). Thermal degradation and flame retardant properties of poly(lactic acid) (PLA) containing 20 wt.\% Phyt/PEI-TA were investigated by TGA, cone calorimetry and microcalorimeter of combustion (PCFC) measurements. TGA results showed that introduction of newly developed Phyt/PEI-TA to PLA significantly improved its thermal stability, as signaled by much more amount of PLA char formed compared to the reference sample. Surprisingly, the use of Phyt/PEI-TA did not decrease the onset degradation temperature of PLA. In agreement with TGA results, the cone calorimetry results approved excellent flame retardancy of PLA upon addition of Phyt/PEITA (36\% reduction in pHRR compared to that of neat PLA). Based on the analysis performed on the remainder of char after cone calorimeter test as well as analyses on HRR curves, the condensed phase action by promoting the formation of char was identified as principal impact of the Phyt/PEI-TA on flame retardancy of PLA. Finally, the performance of developed biobased flame retardant was compared with more than 60 flame retardant systems previously reported in the literature.
\end{abstract}

Keywords: Poly(lactic acid); bio-based flame retardant; flammability

\footnotetext{
Authors to whom correspondence should be addressed:

* Fouad LAOUTID: fouad.laoutid@ materianova.be Phone No.: +32 (0) 65554978

** Henri VAHABI: henri.vahabi@univ-lorraine.fr, Phone No.: +33 (0)3 72749866
} 


\section{Introduction}

Nowadays fire retardancy of polymeric materials has become an important feature of their applications. In this regard, the use of bio-based polymers as substitute for petroleum-based polymers has attracted a great deal of attention. Such green hydrocarbons present much less carbon footprint compared to fossil carbon. Polylactide (PLA) belongs to biopolymer family and can be produced from renewable resources and presents a high stiffness, high degree of transparency in addition to relatively low cost and large production volume.

Flame retardancy is a dynamic research area that has opened new realm of technology to lessen fire risks. When dealing with bio-based flame retardant (FR) systems, sustainability should be considered as an additional requirement. Gas phase FR agents benefit from quenching the flame in the gas phase via formation of radical scavengers, but nowadays they are largely replaced by additives acting in the condensed phase to make possible formation of a protective layer against fire. In contrast to gas-phase-active additives such as halogen-based FR compounds that produce toxics and corrosive smokes, char-forming systems are expected to reduce the amount of harmful volatile compounds released during the combustion.

In the condensed phase, phosphorus-based FRs have particularly appeared effective with polymers containing oxygen [1] because of much less toxic compounds being released compared to halogenated ones [2]. Phosphoric acid produced during thermal decomposition forms into pyrophosphate structures through condensation and generates carbon-carbon double bonds. At higher temperature, crosslinked or carbonized structures are generated via dehydration reaction of the terminal alcohols formed.

Phosphorus based FR additives are usually associated with other synergistic compounds to enhance their efficiency [1]. The use of bio-based char-forming agents, such as lignin [3, 4, 5], starch [6, 7], cellulose [8, 9], $\beta$-cyclodextrin [10, 11] or tannic acid [12] has attracted attention of researchers and engineers alike to reduce environmental impact of FR systems whilst enhancing fire performances.

Lignin is a bio-based phenolic compound receiving much attention in the past decade thanks to its aromatic structure. However, due to its high structural diversity, large molecular weight distribution and variability in terms of reactivity and composition, its performances is strongly dependent on its botanical origin and the extraction process used [4,5]. Using natural and non- 
polymeric bio-based aromatic compounds could present an interesting pathway for overcoming these limitations.

In this work, a novel flame retardant additive composed of small bio-based molecules, i.e. tannic acid (TA) and phytic acid (Phyt) (Figure 1) was prepared. These two additives could present some interest as flame retardant effects on PLA. Tannic acid, that is a non-polymeric phenolic compound, is a char-forming additive under anaerobic condition that enables for the formation of a char layer when associated with phosphorus [12]. In the other hand, phytic acid, the principal form of storage of phosphorus in many plants, has depicted an interesting flame-retardant effect into PLA owing to its high phosphorus content (28wt\%) and an interesting $\mathrm{P} / \mathrm{C}$ atomic ratio (=1). However, due to its liquid form, its incorporation into the PLA induces an important increase of the composite hygroscopy [13].

Combining these two compounds for the preparation of a novel bio-flame retardant agent was the aim of this contribution. Tannic acid and phytic acid were coupled together with the use of branched polyethyleneimine (PEI) to enjoy from either its cationic character or high nitrogen content. In fact, nitrogen-based compounds can act in both condensed and gas phases by promoting the formation of thermally stable condensates as well as by diluting oxygen and combustible gases. This novel bio-based flame retardant agent (Phyt/PEI-TA) was synthesized by a two-step process allowing the combination of phosphorus, carbon and nitrogen in the same complex. Phyt/PEI-TA was characterized using thermogravimetric analysis (TGA), Inductively Coupled Plasma analysis (ICP) and Fourier infrared spectroscopy techniques (FTIR). The effect of its incorporation on PLA thermal and flame-retardant properties was investigated using Size Exclusion Chromatography (SEC), TGA analysis, cone calorimeter test. A flame retardant mode of action of Phyt/PEI-TA was also investigated.

\section{Experimental}

\subsection{Materials}

PLA resin (3051D) with a number-average molecular weight of $100 \quad 000 \mathrm{~g} / \mathrm{mol}$, a polydispersity of 2.1 and D-lactide content of $4.3 \%$ was purchased from NatureWorks. Branched polyethyleneimine (PEI, $50 \mathrm{wt} \%$ in water, $\mathrm{M}_{\mathrm{n}}: 10000 \mathrm{~g} / \mathrm{mol}, \mathrm{M}_{\mathrm{w}}: 25000 \mathrm{~g} / \mathrm{mol}$, Sigma Aldrich), tannic acid (TA, ACS grade, 97\% Aldrich), Potassium carbonate $\left(\mathrm{K}_{2} \mathrm{CO}_{3}\right)$ (Merck), 3,3',4,4'-benzophenone tetra carboxylic dianhydride (BTDA)(Merck), and phytic 
acid (50\% solution, wt\% in water, Sigma Aldrich) were used for the preparation of Phytic acid/Polyethyleneimine/Tannic acid complex (Phyt/PEI-TA).

\subsection{Synthesis of Phy/PEI-TA complex}

First step: synthesis of polyethyleneimine grafted tannic acid (PEI-TA)

In a $250 \mathrm{~mL}$ round-bottomed flask fitted with a stirring bar, polyethyleneimine (PEI) (3.0 g) was added to a solution of tannic acid (Ta) $(3.0 \mathrm{~g})$ in water $(100 \mathrm{~mL}) . \mathrm{K}_{2} \mathrm{CO}_{3}$ was then added to the mixture to raise the $\mathrm{pH}$ to 11 . Stirring was continued at room temperature for $2 \mathrm{~h}$. Then, a solution of 3,3',4,4'-benzophenonetetracarboxylic dianhydride (BTDA) (5.0 g) in DMF (30 $\mathrm{mL}$ ) was added dropwise and stirring was continued for further $24 \mathrm{~h}$ at $70{ }^{\circ} \mathrm{C}$. After cooling the mixture down to room temperature, the precipitates were separated by centrifugation and washed using distilled water and ethanol, respectively. The resulting powder was dried at 80 ${ }^{\circ} \mathrm{C}$ to obtain PEI-TA.

\section{Second step: synthesis of Phytic acid / PEI-TA complex (Phyt/PEI-TA)}

In a $250 \mathrm{~mL}$ round-bottomed flask, PEI-TA powder $(2.0 \mathrm{~g})$ was dispersed in ethanol (100 $\mathrm{mL})$. Phytic acid $(5 \mathrm{~mL})$ was slowly added and the mixture was stirred for $4 \mathrm{~h}$ at room temperature. The obtained solid was separated by centrifugation and dried at $80{ }^{\circ} \mathrm{C}$ in vacuum oven. 
Tannic acid (TA)

Poly(ethylene imine) (PEI)
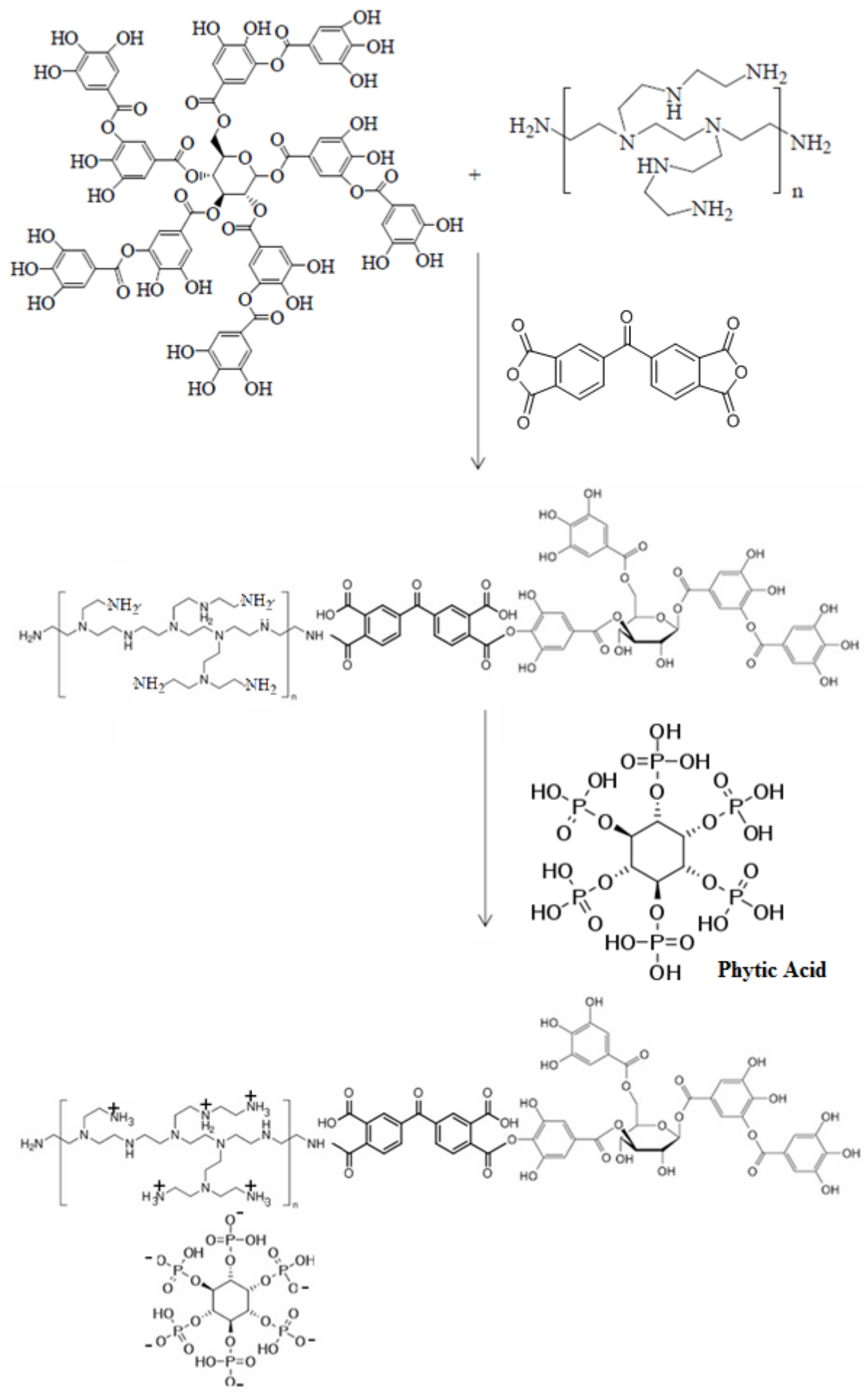

Figure 1: schematic representation of Phyt/PEI-TA structure. 


\subsection{Melt processing}

Blending of Phyt/PEI-TA with the molten PLA was carried out in a Brabender internal mixer at $160{ }^{\circ} \mathrm{C}$ (7 min mixing at $\left.70 \mathrm{rpm}\right)$. Prior to blending, PLA and Phyt/PEI-TA were dried in a vacuum oven at $60{ }^{\circ} \mathrm{C}$ overnight. Plates $\left(100 * 100 * 4 \mathrm{~mm}^{3}\right)$ for cone calorimeter testing were compression-molded at $160{ }^{\circ} \mathrm{C}$ using an Agila PE20 hydraulic press following a precise pressure program: the sample was first deposited for $3 \mathrm{~min}$ on the hot part, it was then pressed for $3 \mathrm{~min} 20 \mathrm{~s}$ at 10 bars, followed by 3 degassing, it was then pressed again for $2 \min 30 \mathrm{~s}$ at 150 bars, and finally the sample was deposited in the cold part and pressed for $5 \mathrm{~min}$. Neat and composite PLA containing $20 \mathrm{wt} \%$ of each Phyt/PEI-TA fraction were prepared.

\subsection{Characterizations}

\subsubsection{Fourier transform infrared (FTIR)}

Fourier transform infrared (FTIR) spectra were gathered on a Perkin-Elmer RXI spectrometer in the range of $400-4000 \mathrm{~cm}^{-1}$ with a resolution of $2 \mathrm{~cm}^{-1}$ and 32 co-added scans, using attenuated total reflection (ATR) mode.

\subsubsection{Inductively Coupled Plasma (ICP)}

Inductively Coupled Plasma (ICP) analysis was recorded with an IRIS Intrepid II (Dual view) from Thermo Fisher Scientific. It was used for determination of the amount of phosphorus in the phosphorylated tannic acid. Before ICP analysis, phosphorus-incorporated samples were prepared by the destruction of the organic matrix by a mineralization process with $\mathrm{H}_{2} \mathrm{SO}_{4} / \mathrm{HNO}_{3} / \mathrm{H}_{2} \mathrm{O}_{2}$ solutions. The amount of phosphorus was determined using a calibration curve obtained from ICP analysis of phosphorus containing standard solutions.

\subsubsection{Size exclusion chromatography (SEC)}

Size exclusion chromatography (SEC) was used to determine the number-average molecular weights of both PLA and PLA/Phyt/PEI-TA blends. The number-average molecular weights and molecular weight distributions were determined in $\mathrm{CHCl}_{3}$ at $23{ }^{\circ} \mathrm{C}$ using an Agilent size exclusion chromatograph equipped with a Knauer 2320 refractometer index detector and two PLGel columns (MIXED-D and 103A). Samples were dissolved in $\mathrm{CHCl}_{3}(5 \mathrm{mg} / 1 \mathrm{~mL}), 20$ $\mu \mathrm{L}$ of the solutions were injected into the columns using a flow rate of $1 \mathrm{~mL} / \mathrm{min}$. Monodisperse polystyrene standards (Polymer Laboratories Ltd.) were used for the primary calibration. 


\subsubsection{Scanning electron microscopy (SEM)}

Morphological investigation was performed to assess the dispersion of Phyt/PEI-TA particles in PLA on a FEI Quanta scanning electron microscopy (SEM) apparatus. PLA composites were cryo-fractured after immersion in liquid nitrogen and then coated with gold sputtering technique to avoid any charging effect during the electron beam scanning.

\subsubsection{Thermogravimetric analysis (TGA)}

Thermal decomposition behavior of tannic acid, phosphorylated tannic acid, pristine PLA and PLA-based composites were studied by thermogravimetric analysis (TGA) using a TGA Q50 device from TA Instruments. Approximately $10 \mathrm{mg}$ of the sample was submitted to a temperature ramp from 100 to $700{ }^{\circ} \mathrm{C}$ at a heating rate of $20{ }^{\circ} \mathrm{C} / \mathrm{min}$. Residual weight at 700 ${ }^{\circ} \mathrm{C}$ (Residue) as well as temperature at the peak of mass loss rate $\left(\mathrm{T}_{\mathrm{deg}}\right)$ and corresponding to $20 \mathrm{wt} \%$ mass loss $\left(\mathrm{T}_{-20 \%}\right)$ were determined.

\subsubsection{Cone calorimeter and Pyrolysis Combustion Flow Calorimeter (PCFC)}

Fire behavior of compositions has been evaluated using mass loss cone calorimeter test at 35 $\mathrm{kW} / \mathrm{m}^{2}$. Cone calorimeter is known as the best technique for assessing the flammability of materials at bench scale. The peak of heat release rate (pHRR) as well as time to ignition (TTI), that are considered as two of the most important parameters in this fire test were recorded accordingly. A high pHRR and a low TTI may cause both fast ignition and rapid-fire propagation. Cone calorimeter tests were performed according to ISO 13927 standard procedures with a FTT mass loss cone calorimeter. Samples $\left(100 * 100 * 3 \mathrm{~mm}^{3}\right)$ were exposed to an external heat flux of $35 \mathrm{~kW} / \mathrm{m}^{2}$, corresponding to common heat flux in a mild fire scenario. The flammability was also studied using a Pyrolysis Combustion Flow Calorimeter (PCFC) from Fire Testing Technology (FTT). Heating rate, maximum pyrolysis temperature, combustion temperature were respectively $1{ }^{\circ} \mathrm{C} / \mathrm{s}, 750{ }^{\circ} \mathrm{C}, 900{ }^{\circ} \mathrm{C}$.

\section{Results and discussion}

\subsection{Structural and thermal properties of Phyt/PEI-TA}

FTIR spectra of PEI-TA and Phyt/PEI-TA are compared in Figure 1 with that of tannic acid. FTIR analysis of the intermediate product formed during the first step (PEI-TA) reveals that in addition to the characteristic absorption bands of both tannic acid and PEI, some new peaks are newly appeared. These new bands are attributed to the formation of amide groups (1665 $\mathrm{cm}^{-1}$ ) and to carboxylic acid $\mathrm{OH}$ groups as well as $\mathrm{NH}_{2}$ functions $\left(2500-3400 \mathrm{~cm}^{-1}\right)$. The 
formation of carboxylic acid $\mathrm{OH}$ groups is a signature of the opening of the dianhydride group of BTDA that reacts with tannic acid, while the formation of amide functional groups hints at the formation of covalent link between PEI and BTDA.

In FTIR spectrum of the final complex (Phyt/PEI-TA), the presence of phytic acid has been confirmed by the presence of the absorption band at $998 \mathrm{~cm}^{-1}$ corresponding to $\mathrm{P}-\mathrm{O}$ bond.

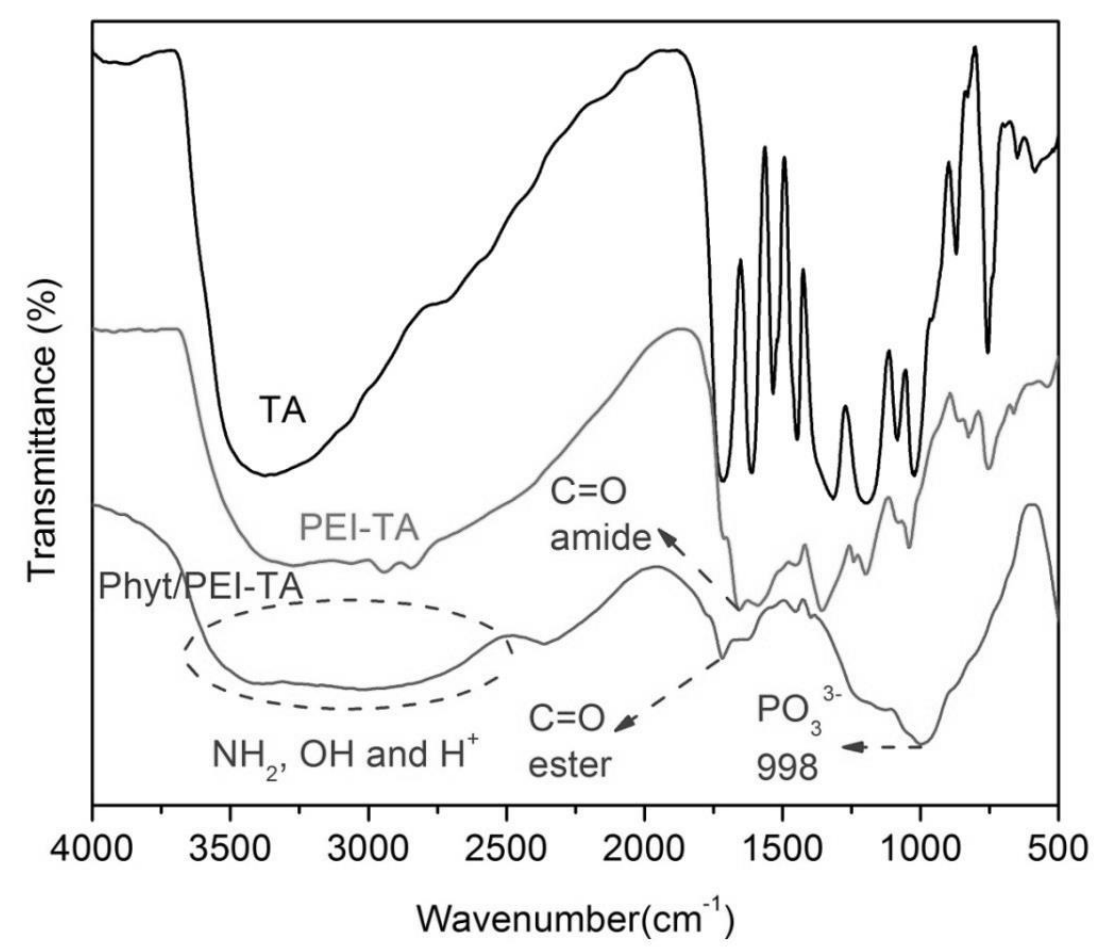

Figure 2: FTIR spectra of TA, PEI-TA and Phyt/PEI-TA.

The structure of Phyt/PEI-TA has been further investigated by determining its chemical composition. ICP analysis was used to quantify its phosphorus, nitrogen and carbon content. The results presented in Table 1 make evident that the synthesis method applied in this work enables for developing a compound predominantly composed of carbon (26.4 wt $\%$ ) and contains a high phosphorus and nitrogen content, i.e. $14 \mathrm{wt} \%$ and $4.9 \mathrm{wt} \%$ respectively. Moreover, Phyt/PEI-TA presents an interesting $\mathrm{C} / \mathrm{P} / \mathrm{N}$ ratio. 


\begin{tabular}{|l|c|c|c|}
\hline & $\begin{array}{c}\mathrm{P} \\
(\mathrm{wt} \%)\end{array}$ & $\begin{array}{c}\mathrm{N} \\
(\mathrm{wt} \%)\end{array}$ & $\begin{array}{c}\mathrm{C} \\
(\mathrm{wt} \%)\end{array}$ \\
\hline Phyt/PEI-TA & 14 & 4.9 & 26.4 \\
\hline Residue after combustion & 13.1 & 2.4 & 39.2 \\
\hline
\end{tabular}

Table 1: phosphorus, nitrogen and carbon content determined by ICP analysis.

The thermal stability of Phyt/PEI-TA has been first investigated to test whether the product could be melt processed with PLA at $160{ }^{\circ} \mathrm{C}$. Fig. 3 presents thermo-oxidative and anaerobic decomposition of the product. According to the curves, no important thermal degradation took place below $200{ }^{\circ} \mathrm{C}$ and only a small weight loss of about $5 \mathrm{wt} \%$, probably due to some water release, is recorded at $160{ }^{\circ} \mathrm{C}$. The product must therefore be dried prior melt processing. TGA analysis has further been used to investigate the thermal behavior of produced additive and its char forming ability. Results suggest that thermal decomposition of the product takes place over a large temperature range signifying several decomposition steps. No clear separation between these steps can be distinguished since several of them overlap with each other. The comparison of TGA curve under air of Phy/PEI-TA with those of tannic and phytic acid gives some interesting information. First, we can observe that below $550{ }^{\circ} \mathrm{C}$, TGA curve of Phyt/PEI-TA is very similar to that of the more thermally stable compound, i.e. phytic acid. Moreover, the presence of tannic acid, which undergoes important mass loss between 250 and $350{ }^{\circ} \mathrm{C}$ did not affect Phyt/PEI-TA thermal stability. The presence of TA in combination with phytic acid and PEI enables avoiding its thermal degradation. Another advantage of combining phytic acid and tannic acid lies to the increase of the amount of char formed at 700 ${ }^{\circ} \mathrm{C}$. In fact, at the end of TGA analysis, the amount of char is of about $53 \%$ in the case of Phyt/PEI-TA (53\%) and is higher to that obtained with phytic acid (25\%). Tannic acid decomposes totaly and any residue is left at the end of the analysis.

Moreover, TGA curves of Phy/PEI-TA, under air and nitrogen (Fig. 3b) evidence that its thermal behavior is not affected by the nature of gas used below $600{ }^{\circ} \mathrm{C}$. Above $600{ }^{\circ} \mathrm{C}$, some thermo-oxidative degradation of the char occurs but it does not significantly affect its amount at $700{ }^{\circ} \mathrm{C}$, which is an important feature that remains almost high, i.e. $53 \%$ under air and $60 \%$ under $\mathrm{N}_{2}$. It is worth mentioning that at the end to TGA analysis, an intumescent and porous char layer is left (Fig. 4). Phyt/PEI-TA can thus be considered to be a charring additive under both oxidant and anaerobic conditions. The high phosphorus content of Phyt/PEI-TA together 
with the presence of tannic acid into its structure are mainly responsible for its high char forming ability. The combination of phosphorous and tannic acid enabled for the generation of important char residue during thermal decomposition [12].

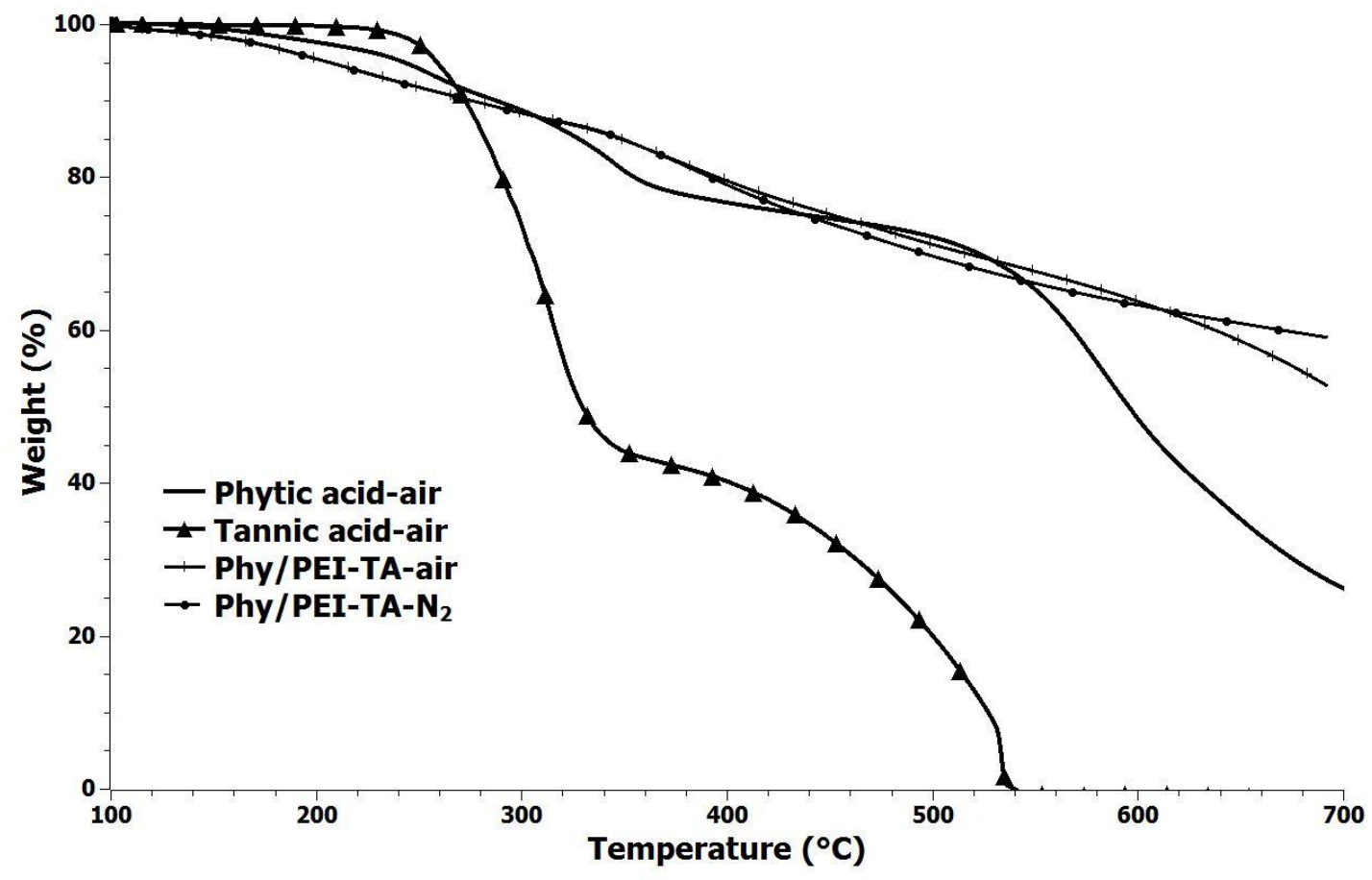

Figure 3: TGA curves of Phytic and tannic acid, under air, and Phyt/PEI-TA compound under both air and $\mathrm{N}_{2}$ atmosphere $\left(20^{\circ} \mathrm{C} / \mathrm{min}\right)$.
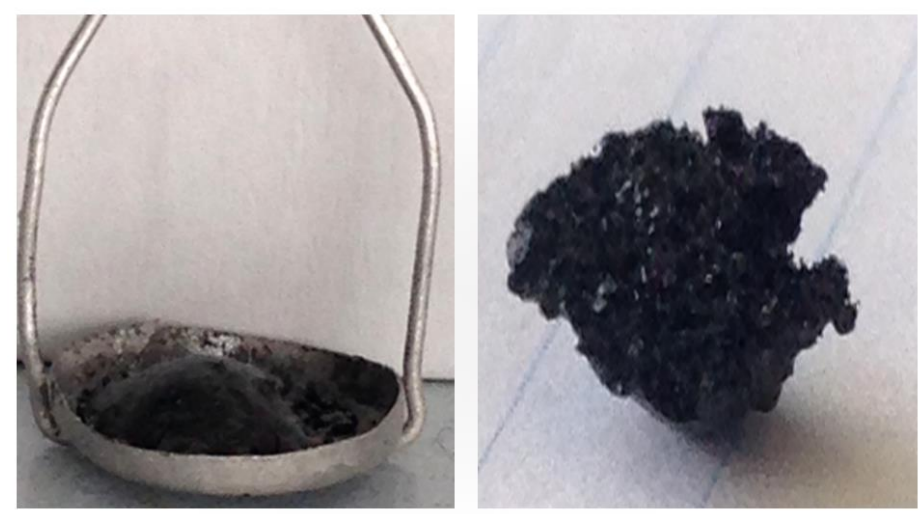

Figure 4: images of the char formed during TGA analysis (under air) of Phyt/PEI-TA. 


\subsection{Effect of Phyt/PEI-TA on thermal stability and flame-retardant behavior of PLA}

Based on TGA results, Phyt/PEI-TA could be advantageously used for enhancing PLA flame retardant behavior thanks to its high char forming ability. Having this in mind, $20 \mathrm{wt} \%$ of this novel additive was incorporated into PLA by melt processing. It is worth mentioning that the incorporation of Phyt/PEI-TA does not induce any significant degradation of PLA during melt processing; In fact, SEC analysis (Table 2) shows that the number-average molecular weight of PLA decreased only from $99000 \mathrm{~g} / \mathrm{mol}$ to $79000 \mathrm{~g} / \mathrm{mol}$ in the presence of $20 \mathrm{wt} \%$ Phyt/PEI-TA. SEM images taken from composite sample (Fig. 5) show that the Phyt/PEI-TA complex is constituted of small spherical micro-sized particles ( 1 to $20 \mu \mathrm{m}$ ) that are very well dispersed in PLA.

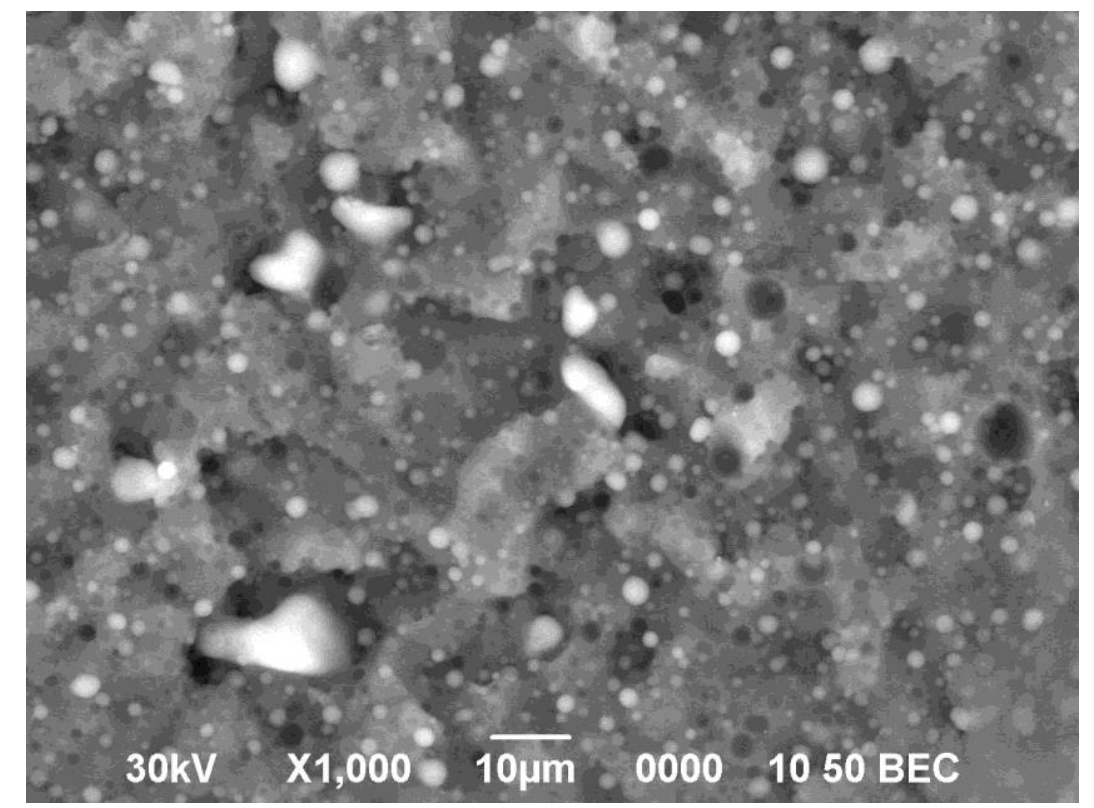

Figure 5: SEM image of the composite morphology.

\subsubsection{Thermal behavior}

The effect of the addition of Phyt/PEI-TA particles on PLA thermal stability has been investigated using TGA analysis under both oxidant and anaerobic condition (Fig. 6). The temperatures at $20 \%$ weight loss $\left(\mathrm{T}_{-20 \%}\right)$ and at the maximum weight loss rate $\left(\mathrm{T}_{\max }\right)$ as well as the char yield at $700{ }^{\circ} \mathrm{C}$ were determined from TGA and DTG curves, and the values are summarized in Table 2.

Thermal and thermo-oxidative degradations of PLA are single stage processes, starting at 320 ${ }^{\circ} \mathrm{C}$ under nitrogen and $300{ }^{\circ} \mathrm{C}$ under air, without formation of any residue at $700{ }^{\circ} \mathrm{C}$. 
The initial decomposition temperature of PLA under inert atmosphere $\left(320^{\circ} \mathrm{C}\right)$ is higher to that obtained under oxidizing conditions $\left(300^{\circ} \mathrm{C}\right)$, evidencing that the onset bond scission is sensitive to thermal-oxidation.

The incorporation of Phyt/PEI-TA into PLA was found to induce important changes in the composite thermal stability. Regardless of the testing atmosphere, the incorporation of Phyt/PEI-TA shifts TGA curves toward higher temperatures, since $300{ }^{\circ} \mathrm{C}$ and $320{ }^{\circ} \mathrm{C}$ under air and nitrogen atmosphere respectively . In contrast to unfilled PLA, the composite thermal stability is not affected by the presence of oxygen since $\mathrm{T}_{-5 \%}, \mathrm{~T}_{-20 \%}$ and $\mathrm{T}_{\max }$ recorded for the composite under air $\left(360{ }^{\circ} \mathrm{C}, 390{ }^{\circ} \mathrm{C}\right.$ and $\left.412{ }^{\circ} \mathrm{C}\right)$ are very close to those under inert atmosphere $\left(366^{\circ} \mathrm{C}, 395^{\circ} \mathrm{C}\right.$ and $\left.417^{\circ} \mathrm{C}\right)$.

The calculated TGA curves (linear addition of the weight loss of the components degraded separately under air and nitrogen atmosphere) for PLA containing $20 \mathrm{wt} \%$ Phyt/PEI-TA was compared to the experimental curves in order to evaluate the interaction between PLA and Phyt/PEI-TA during the degradation, Figure 7. When PLA and Phyt/PEI-TA are separately degraded without interaction, it could be expected that the calculated TGA curve might be similar to that of experimental one. Interestingly, the comparison of calculated and experimental curves is revealed a significant difference. The calculated curves, in both $\mathrm{N}_{2}$ and air atmospheres, showed less thermal stability than experimental curves which evidences the presence of some interactions between PLA and Phyt/PEI-TA during the degradation. However, the obtained char quantity is similar in calculated and experimental curves.

Thus, the use of Phyt/PEI-TA enables enhancing PLA thermal stability as well as modifying its thermal decomposition pathway from non-charring to char forming degradation. Its use strongly limits the composite thermal-oxidation owing to its char forming ability that limits oxygen diffusion through the material. At $700{ }^{\circ} \mathrm{C}$, a final residue of about $10 \%$ is left under oxygen and $12.5 \%$ under nitrogen. A small difference between the residue yield formed under anaerobic and oxidant conditions evidence the important resistance of the residue against oxidation.

In conclusion, the incorporation of Phyt/PEI-TA enables for significant improvement of PLA thermal stability and to the formation of thermally stable char residue whatever the testing atmosphere. Thanks to these positive effects, it is expected that the incorporation of Phyt/PEITA into PLA enables for obtaining a material with improved flame retardant behavior. 

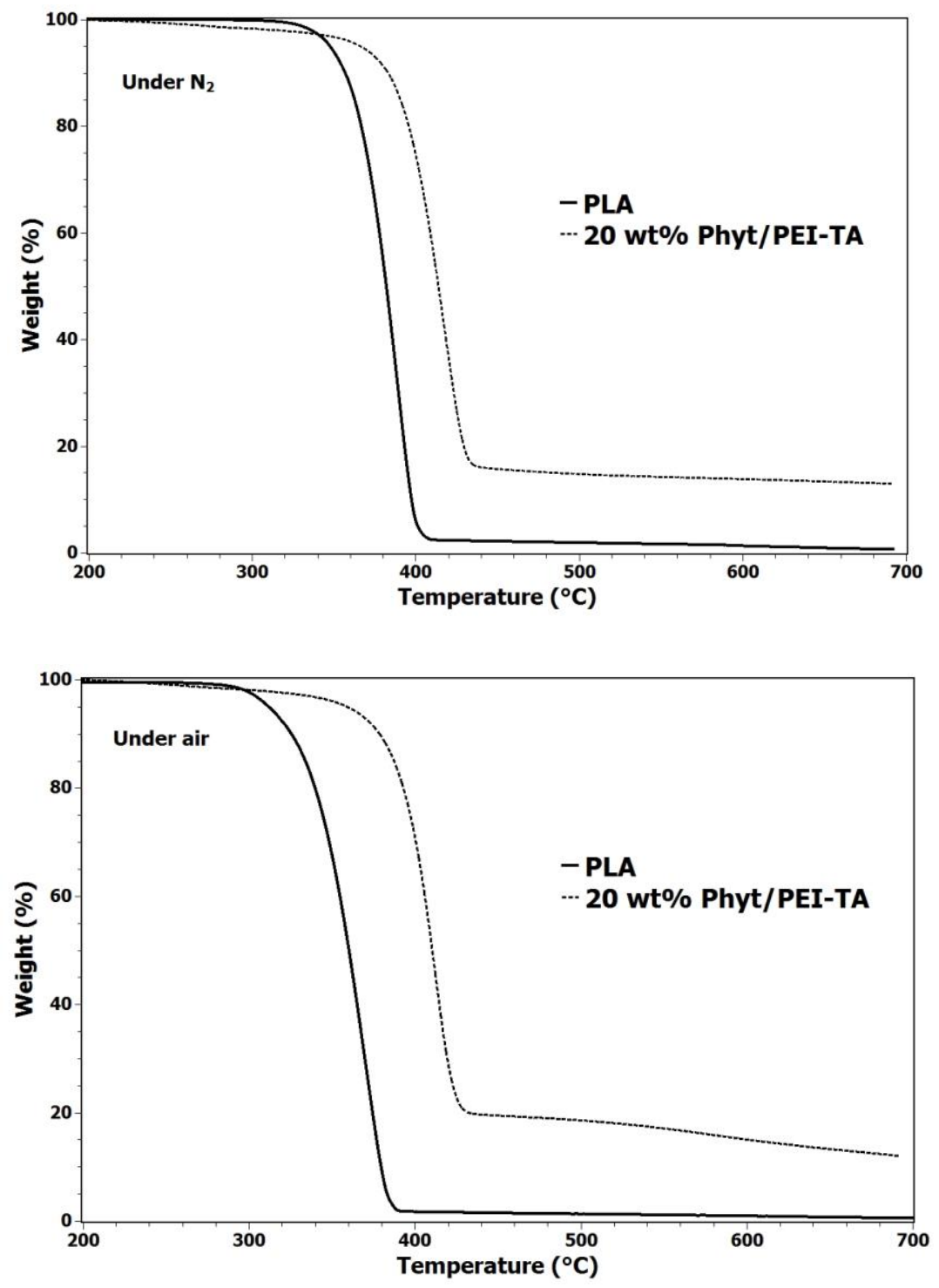

Figure 6: TGA curves of PLA and PLA containing $20 \mathrm{wt} \%$ Phyt/PEI-TA under nitrogen and air atmospheres $\left(20^{\circ} \mathrm{C} / \mathrm{min}\right)$.
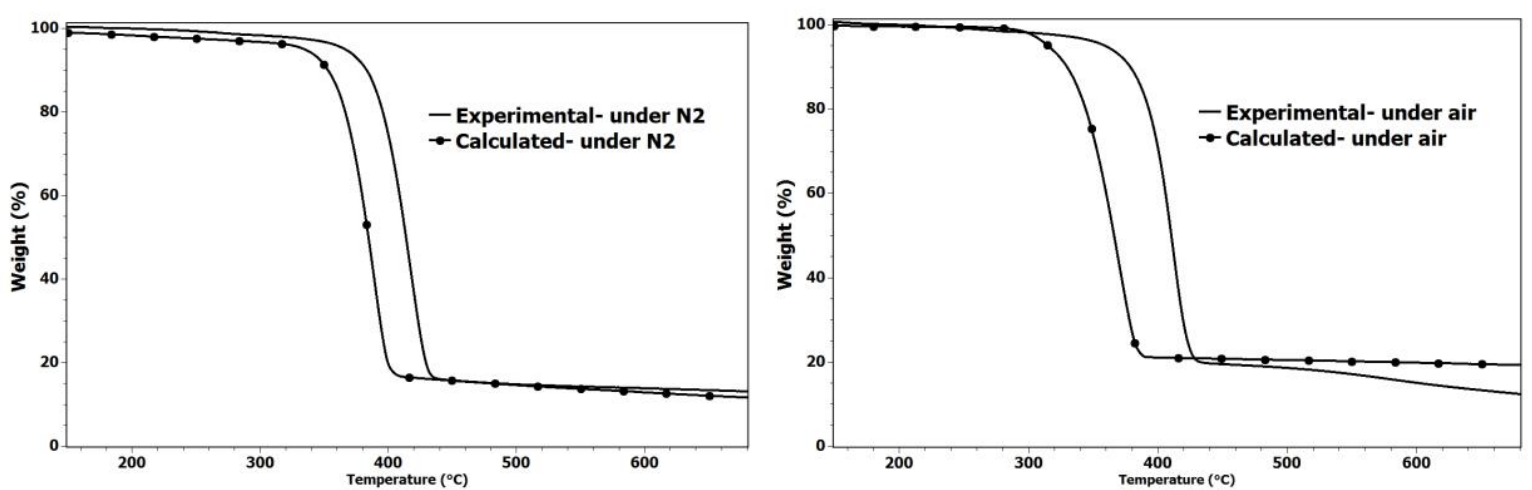

Figure 7: Calculated and experimental TGA curves for PLA containing $20 \mathrm{wt} \%$ Phyt/PEI-TA. 


\begin{tabular}{|c|c|c|c|c|c|c|c|c|c|}
\hline & \multicolumn{4}{|c|}{ TGA (under $\mathbf{N}_{2}$ ) } & \multicolumn{4}{|c|}{ TGA (under air) } & \multirow{2}{*}{$\begin{array}{c}\text { SEC } \\
\begin{array}{c}\mathrm{M}_{\mathrm{n}} \\
(\mathrm{g} / \mathbf{m o l})\end{array}\end{array}$} \\
\hline & $\begin{array}{l}\mathbf{T}_{-5 \%} \\
\left({ }^{\circ} \mathbf{C}\right)\end{array}$ & $\begin{array}{l}\mathbf{T}_{-20 \%} \\
\left({ }^{\circ} \mathbf{C}\right)\end{array}$ & $\begin{array}{l}\mathbf{T}_{\max } \\
\left({ }^{\circ} \mathbf{C}\right)\end{array}$ & $\begin{array}{c}\text { Residue } \\
\quad(\%)\end{array}$ & $\begin{array}{l}\text { T. } .5 \% \\
\left({ }^{\circ} \mathbf{C}\right)\end{array}$ & $\begin{array}{l}\text { T.20\% }_{-2} \\
\left({ }^{\circ} \mathbf{C}\right)\end{array}$ & $\begin{array}{l}\mathbf{T}_{\max } \\
\left({ }^{\circ} \mathbf{C}\right)\end{array}$ & $\begin{array}{c}\text { Residue } \\
\text { (\%) }\end{array}$ & \\
\hline PLA & 347 & 366 & 390 & 0 & 313 & 340 & 370 & 0 & 99000 \\
\hline $20 \mathrm{wt} \%$ Phyt/PEI-TA & 366 & 395 & 417 & 12.5 & 360 & 390 & 412 & 10 & 79000 \\
\hline
\end{tabular}

Table 2: TGA and SEC data of pristine PLA and composite containing $20 \mathrm{wt} \%$ Phyt/PEI-TA.

\subsubsection{Fire behavior}

Figures $8 \mathrm{~A}$ and $8 \mathrm{~B}$ show the heat release rate curves of PLA and PLA containing $20 \mathrm{wt} \%$ Phyt/PEI-TA. Pristine PLA exhibits a strong combustion, starting after $34 \mathrm{~s}$, consuming all the material and releasing a total heat of about $66.7 \mathrm{MJ} / \mathrm{m}^{2}$ with a pHRR of $670 \mathrm{~kW} / \mathrm{m}^{2}$. In the presence of Phyt/PEI-TA, curves and Table 3, an important decrease in both pHRR (-36 \%) and THR $(-13 \%)$. The incorporation of Phyt/PEI-TA did not induce any improvement of the composite resistance to ignition. In fact, only a slight change of the time to ignition from $34 \mathrm{~s}$ to $26 \mathrm{~s}$ has been observed. This result does not support the improvement of the thermal stability observed during TGA analysis and demonstrate that no correlation could be done between thermal stability during TGA analysis and time to ignition during cone calorimeter test. In fact, several factors such as sample shape and weight, thermal conductivity and diffusivity are dependent on the type of the analysis. A significant change in the shape of HRR curve is noticed from unimodal to bimodal curve. HRR curve of PLA/Phyt/PEI-TA blend is characteristic of a thermally thick charring material while that of unfilled PLA is characteristic of thermally thin samples according to the classification of Schartel and Hull [13]. In fact, HRR curve of pristine PLA presents a sharp HRR peak, indicating that the whole sample is pyrolyzed at the same time while a second HRR peak, corresponding to the char cracking and to the release of further combustible compounds, is recorded for the composite.

The pHRR reduction is due to the presence of Phyt/PEI-TA that induced the formation of a char residue during the combustion. A residue of about $19.4 \%$ is left at the end of the combustion (Table 3). Macroscopic scale observation shows the formation of a cohesive char layer (Fig. 9) while microscopic scale analysis confirms that its structure is not porous but very compact (Fig. 10). 
These results clearly evidence that the presence of phosphorus in the FR additive structure greatly enhances the FR properties of the composite. It is worth remembering that thanks to its high phosphorus content (14 wt\%), the incorporation of Phyt/PEI-TA, even at only 20 $\mathrm{wt} \%$, enables reaching an interesting phosphorus content in the composite, i.e. $2.8 \mathrm{wt} \%$. Tannic acid, that is also another constituent of Phyt/PEI-TA complex, similarly assisted in promoting char formation during the combustion. Tannic acid has been reported to act in the condensed phase through the formation of an effective char layer, especially when combined with phosphorus [12].
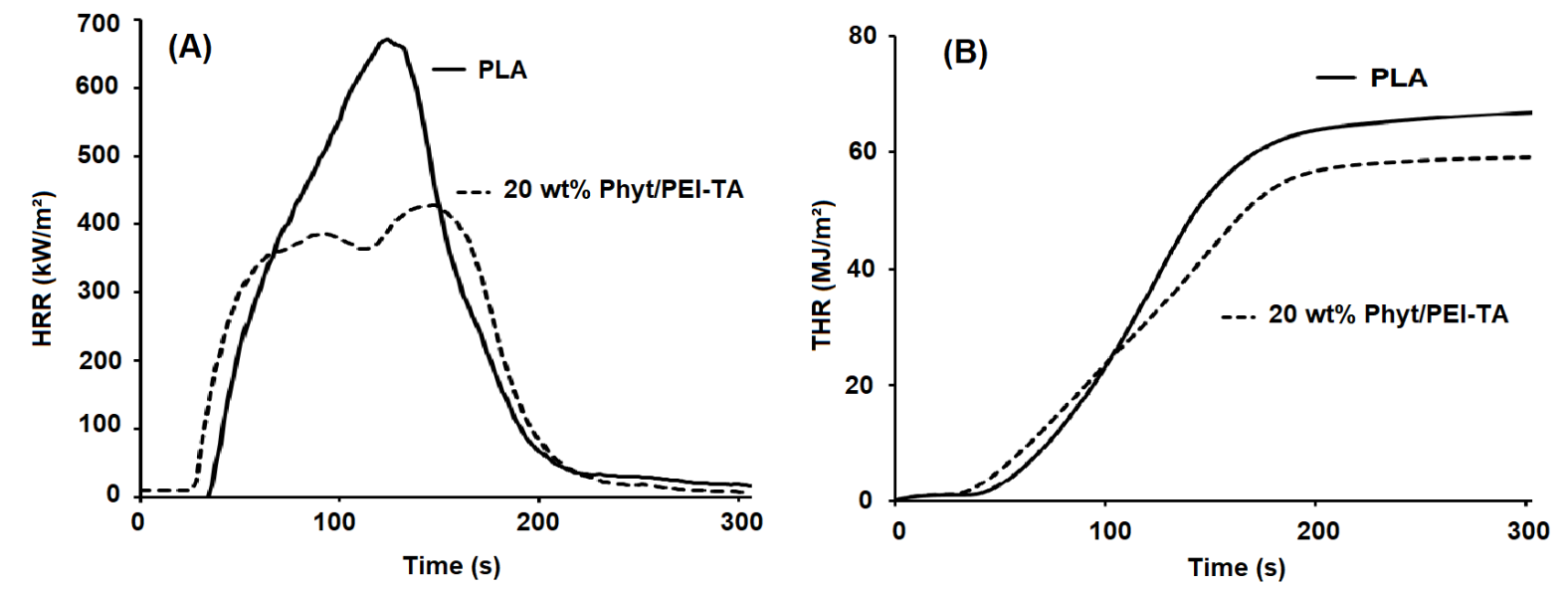

Figure 8: (A) Heat release rate and (B) total heat release of PLA and PLA containing 20wt\% Phyt/PEI-TA from cone calorimeter test (irradiance: $35 \mathrm{~kW} / \mathrm{m}^{2}$ ).

\begin{tabular}{|c|c|c|c|c|c|c|}
\hline & $\begin{array}{l}\text { TTI } \\
(\mathrm{s})\end{array}$ & $\begin{array}{c}\text { pHRR } \\
\left(\mathrm{kW} / \mathrm{m}^{2}\right)\end{array}$ & $\begin{array}{c}\text { pHRR } \\
\text { reduction (\%) }\end{array}$ & $\begin{array}{c}\text { THR } \\
\left(\mathbf{M j} / \mathbf{m}^{2}\right)\end{array}$ & $\begin{array}{c}\text { THR reduction } \\
(\%)\end{array}$ & $\begin{array}{c}\text { Residue } \\
(\%)\end{array}$ \\
\hline PLA & 34 & 670 & - & 67 & - & 0 \\
\hline $20 \mathrm{wt} \%$ Phyt/PEI-TA & 26 & 428 & -36 & 58 & -13 & 19.4 \\
\hline
\end{tabular}

Table 3: Cone calorimeter results $\left(35 \mathrm{~kW} / \mathrm{m}^{2}\right)$ 


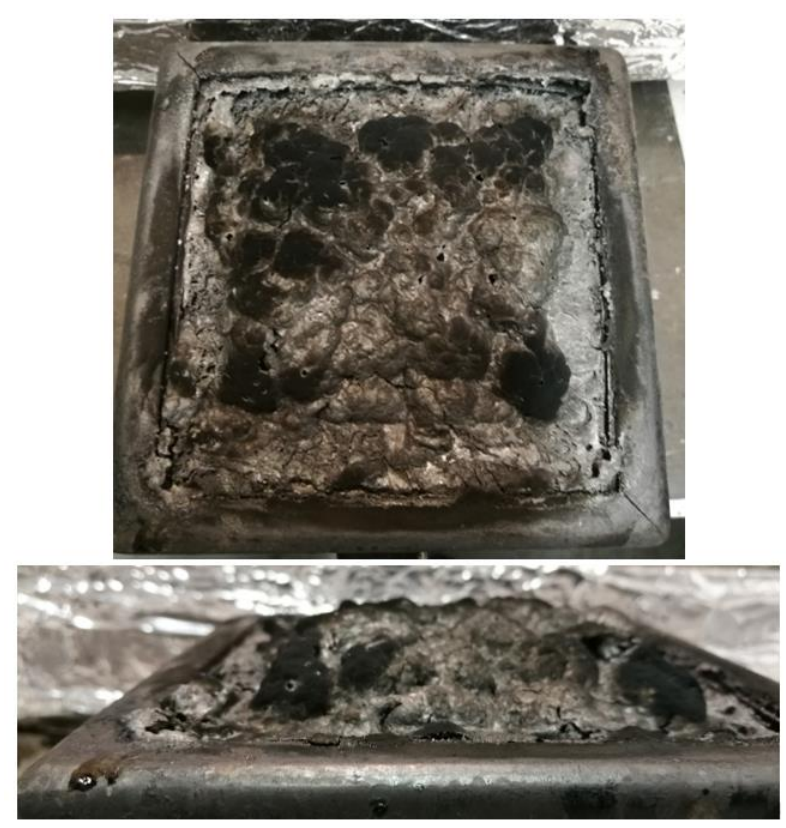

Figure 9: photographs of the residues remaining after the cone calorimeter test.
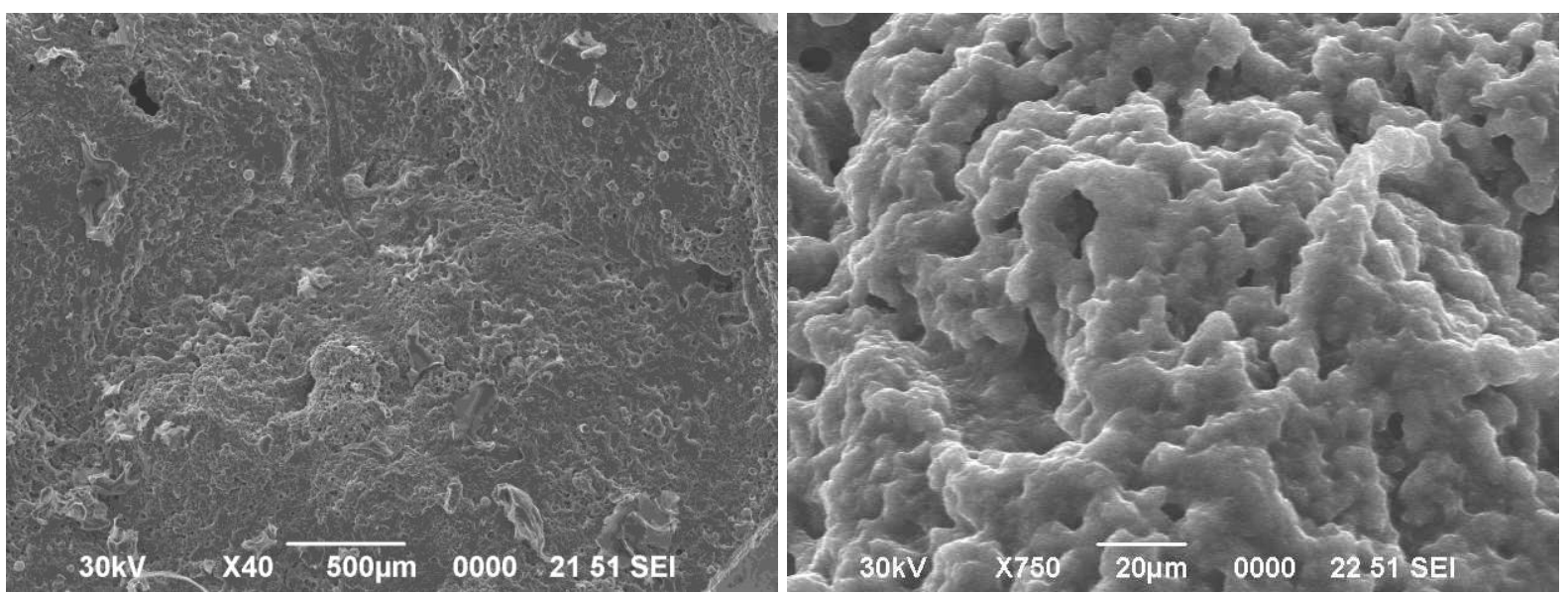

Figure 10: SEM images of the char residue obtained after the cone calorimeter.

The residue of cone calorimeter test was analyzed by Inductively Coupled Plasma (ICP) analysis to determine its phosphorus, nitrogen and carbon content. Table 1 presents the results and evidences that using Phyt/PEI-TA FR additive enables for the formation of a carbon-rich char composed by $39 \mathrm{wt} \%$ carbon. Moreover, it was possible to compare the evolution of $\mathrm{P}$ and $\mathrm{N}$ amount before and after the combustion (Fig. 11). It was found that the phosphorus mainly (more than $90 \mathrm{wt} . \%$ ) remains in the condensed phase demonstrating that the presence of Phyt/PEI-TA induces mainly a condensed phase action with a barrier effect. This result is not surprising since both tannic and phytic acid based flame retardant agents have been found to act in the condensed phase by promoting the formation of char layer [12, 14]. However, some gas phase action is not excluded since some nitrogen is lost during the combustion. 


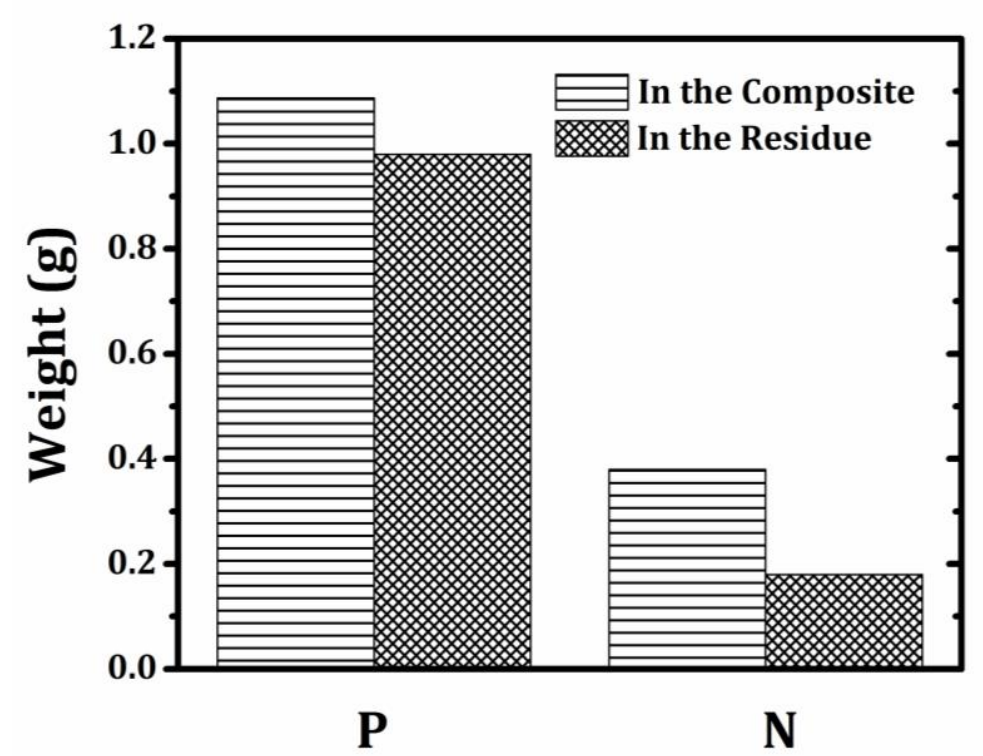

Figure 11: mass of phosphorus and nitrogen in the composite before the combustion and after the combustion in the residue.

The flammability was also investigated using Pyrolysis Combustion Flow Calorimeter (PCFC) test. Figure 12 displays HRR curves of PLA and PLA containing $20 \mathrm{wt} \%$ Phyt/PEITA. It is worth mentioning that samples used during PCFC analysis (few $\mathrm{mg}$ ) were very smaller than those used during cone calorimeter test (around $40 \mathrm{~g}$ ). This makes the comparison between PCFC and cone calorimeter results very difficult. However, PCFC test results can provide precious information on the flammability of the released gases that could reveal any changes of the chemical nature of the degradation product.

HRR curves obtained during PCFC tests showed that both PLA and the composite exhibit one heat release rate. Moreover, the incorporation of Phyt/PEI-TA into the PLA was really beneficial and had two important impacts on PLA flammability. First, the peak of HRR and Total Heat Release (THR) were decreased from 550 to $330 \mathrm{~W} / \mathrm{g}$ (-40\%) and from 17 to 13.8 $\mathrm{kJ} / \mathrm{g}$ respectively. Second, and in accordance with TGA measurements, the temperature of pHRR was shifted from 362 to $376{ }^{\circ} \mathrm{C}$ owing to the enhancement of the composite thermal stability. The decrease in both pHRR and THR recorded in the presence of Phyt/PEI-TA is due to its ability to form a char even during anaerobic composite decomposition (Figure 6). As a consequence, the amount of gases decreases since a part of both polymer and additive remains in the condensed phase. 


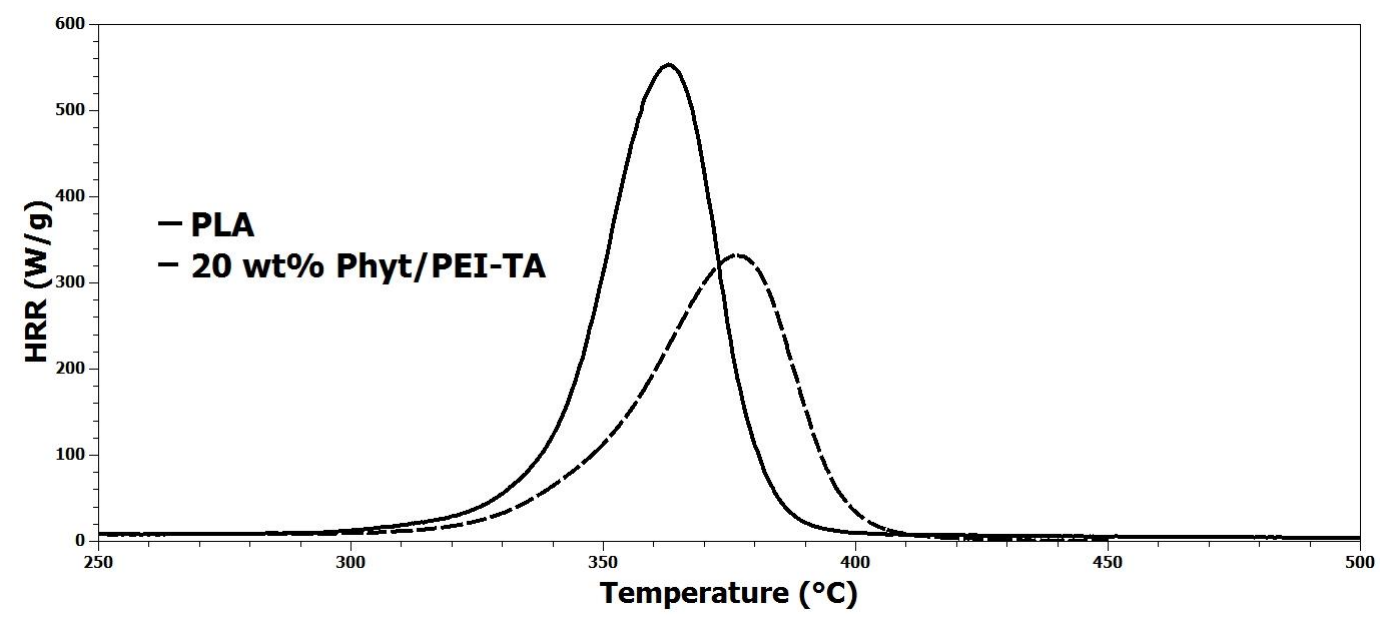

Figure 12: Heat Release Rate (HRR) curves obtained from PCFC tests.

The performance of new bio-based flame retardant (Phyt/PEI-TA) in PLA was compared to different flame retardant for PLA (bio and non-biobased FR) through a detailed review of the literature, Fig. 13 and Annexe 1. The comparison was performed by a focus on more than 60 flame retardant systems. Two important values were extracted from the literatures which are flame retardant content and reduction in pHRR, Annexe1. The reduction in pHRR was then plotted as a function of flame retardant content (wt\%), Fig.13. It must be noted that even if some parameters such as heat flux and PLA grade in different works, however we compared only "the reduction in pHRR". First, we can observe that flame retardants used in PLA are not mostly bio-based (black points, Fig.13). Secondly, our flame retardant (Phyt/PEI-TA), with $36 \%$ reduction in pHRR, offers a relatively acceptable performance compared to other biobased flame retardants. 


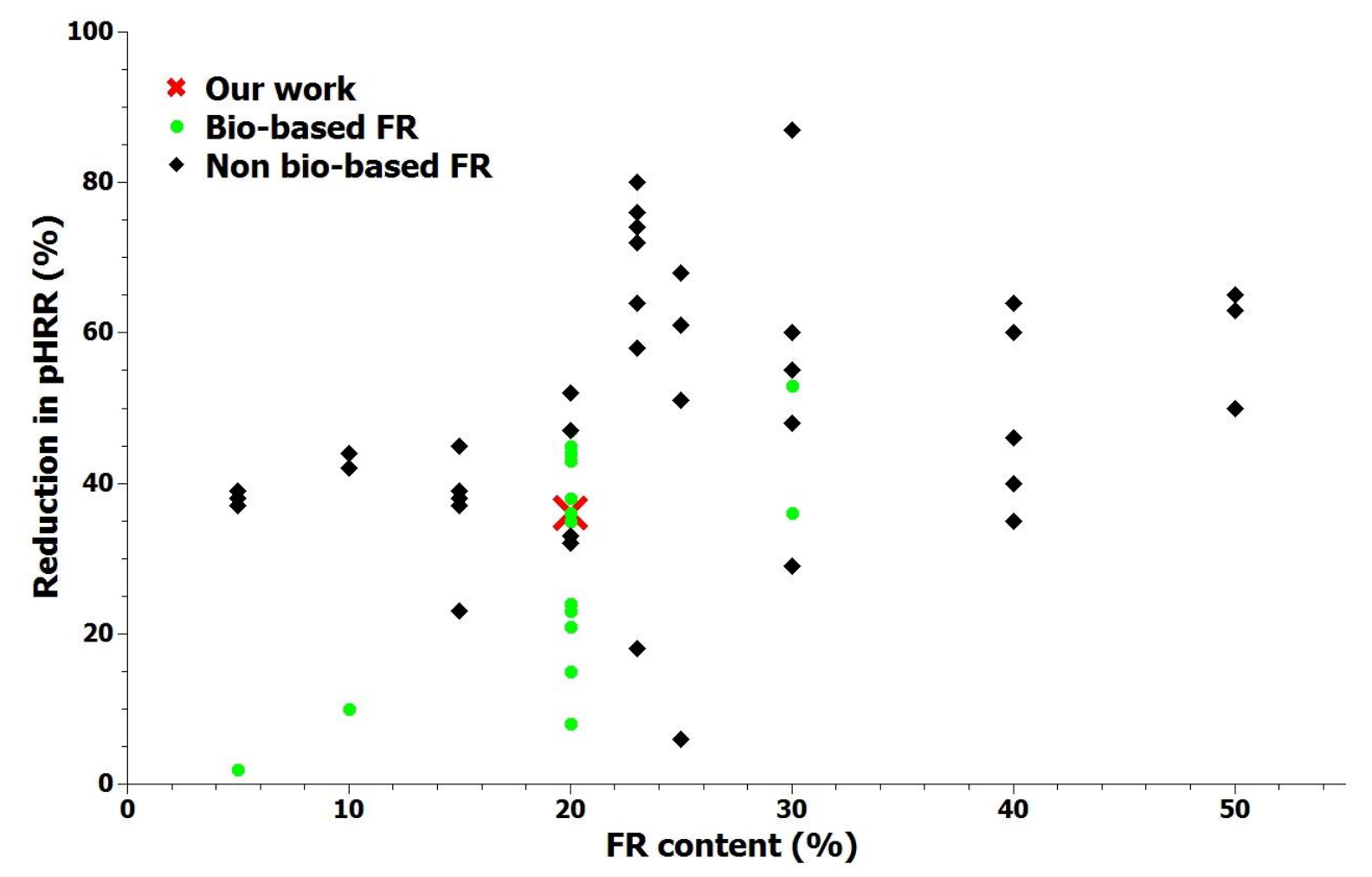

Figure 13: Reduction in pHRR as a function of flame retardant content for PLA systems (bio-based FR and non-bio-based flame retardant points were collected from the literature).

This performance would be of higher importance considering the effect of the FR additive on PLA thermal degradation during melt processing (Table 2). In the presence of newly developed bio-based flame retardant (Phyt/PEI-TA), PLA underwent limited thermal degradation and its molar mass decreased from 99000 to $79000 \mathrm{~g} / \mathrm{mol}(-20.3 \%)$. This result was compared to the reduction of PLA molar mass obtained with other bio-based flame retardant from the literature as well as the reduction in pHRR of each system. Figure 14 displays this investigation and shows that only one bio-based flame retardant induces lower PLA thermal degradation but without leading to any significant $\mathrm{pHRR}$ reduction. 


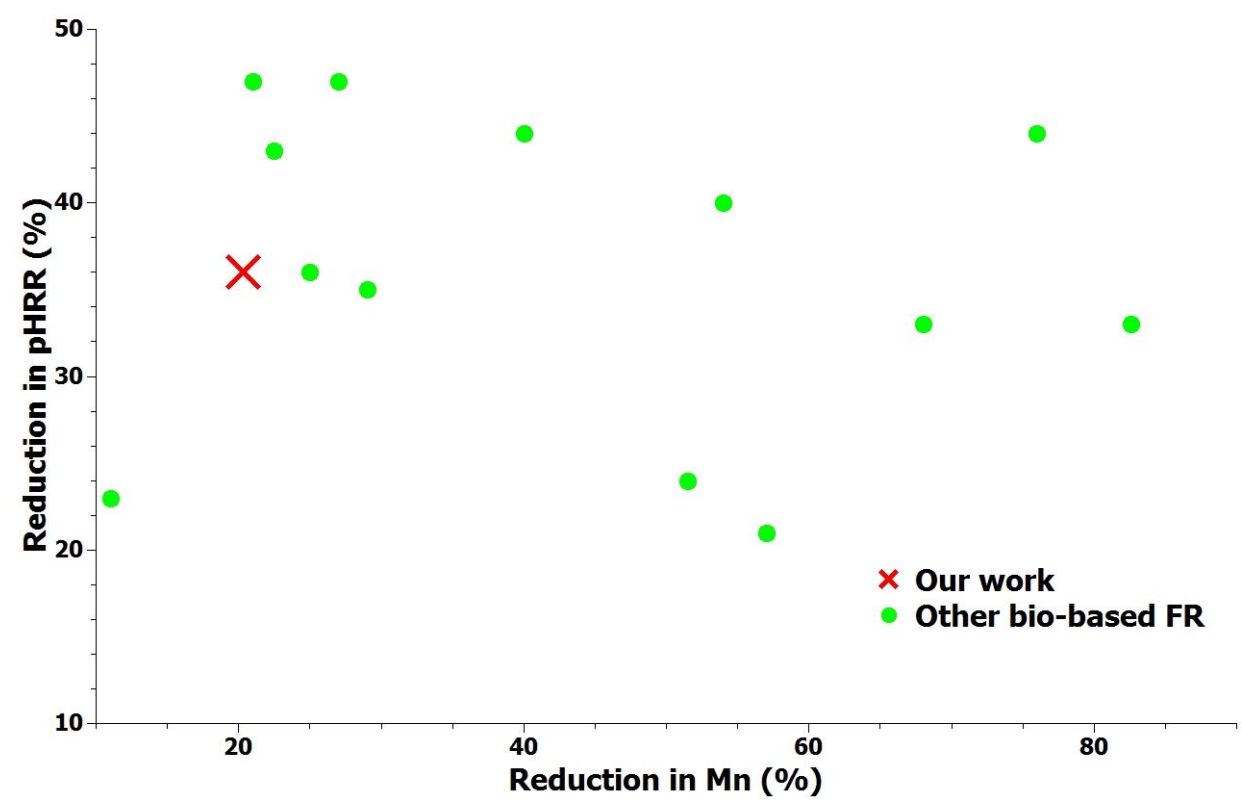

Figure 14: Reduction in pHRR as a function of reduction in molar mass (Mn) (other bio-based FR points were collected from the literature).

\section{Conclusion}

This paper reports on the synthesis and the flame retardant action of a novel bio-based Phosphorus-Nitrogen containing flame retardant additive (Phyt/PEI-TA) for PLA. Phyt/PEITA was prepared by coupling two bio-based compounds together, i.e. tannic acid and phytic acid. These two molecules were successfully linked thanks to the action of cationic branched polyethyleneimine (PEI) and 3,3',4,4'-benzophenonetetracarboxylic dianhydride. The resulting FR agent was characterized using several techniques (FTIR, TGA and ICP). TGA data show that Phyt/PEI-TA thermal degradation enables for obtained char residue under both anaerobic and oxidant conditions owing to its composition (13\% of phosphorus, $2.4 \%$ of nitrogen and $39 \%$ of carbon). The thermal stability as well as fire retardancy performance of PLA containing $20 \mathrm{wt} \%$ Phyt/PEI-TA were then examined. SEM observations showed well dispersed Phyt/PEI-TA microparticles into the PLA. TGA analysis evidenced significant enhancement of the composite thermal stability in comparison with pristine PLA. Furthermore, the presence of Phyt/PEI-TA in PLA did not affect the onset of degradation. Moreover, the distinct difference between the calculated and experimental TGA results indicated a strong interaction between Phyt/PEI-TA and PLA during the degradation. Composite containing $20 \mathrm{wt} \%$ Phyt/PEI-TA exhibited improved flame retardant properties during cone calorimeter test since both pHRR and THR were reduced by $36 \%$ and $13 \%$, 
respectively. However, a slight decrease in TTI was to deplore. In addition to cone calorimetry results, the investigation of char residue revealed that the principal action of Phyt/PEI-TA was in the condensed phase by promoting the formation of char and providing the flame retardancy by barrier effect. Finally, the comparison of obtained results in this study and those of the literature revealed the properness of our new bio-based flame retardant. 
Annex 1: collected data from the literature on "Flame retardancy of PLA".

\begin{tabular}{|c|c|c|c|c|}
\hline $\mathbf{N}^{\circ}$ & Name(s) of Flame retardant(s), incorporated into PLA & $\begin{array}{c}\text { Wt.\% } \\
\text { FR }\end{array}$ & $\begin{array}{c}\text { Reduction in pHRR } \\
(\%)\end{array}$ & Ref. \\
\hline 1 & Melamine/APP & 30 & 87 & 16 \\
\hline 2 & APP/PER & 40 & 64 & 17 \\
\hline 3 & APP/LIG & 40 & 46 & 17 \\
\hline 4 & APP/starch & 40 & 40 & 17 \\
\hline 5 & MCAPP/lignin & 23 & 58 & 18 \\
\hline 6 & $\begin{array}{l}\text { MCAPP/Lignin/octadecyl trimethylammonium and } \\
\text { cetyltrimethylammonium }\end{array}$ & 23 & 76 & 18 \\
\hline 7 & $\begin{array}{l}\text { MCAPP/Lignin/methyl tallow bis(2-hydroxyethyl) } \\
\text { ammonium }\end{array}$ & 23 & 80 & 18 \\
\hline 8 & $\begin{array}{l}\text { MCAPP/Lignin/dioctadecyl dimethyl ammonium } \\
\text { bromide }\end{array}$ & 23 & 72 & 18 \\
\hline 9 & Melamine/APP & 30 & 29 & 19 \\
\hline 10 & Melamine/APP/MMT & 30 & 60 & 19 \\
\hline 11 & APP & 23 & 18 & 20 \\
\hline 12 & APP/ modified lignin & 23 & 74 & 20 \\
\hline 13 & APP/lignin & 23 & 64 & 20 \\
\hline 14 & APP & 15 & 23 & 21 \\
\hline 15 & APP/expandable graphite & 15 & 39 & 21 \\
\hline 16 & APP/PER & 15 & 37 & 22 \\
\hline 17 & $\mathrm{PP} /$ nanofibrillated cellulose & 15 & 38 & 22 \\
\hline 18 & PP/POSS-modified nanofibrillated cellulose & 15 & 45 & 22 \\
\hline 19 & MPP & 20 & 33 & 22 \\
\hline 20 & OP1311 & 25 & 6 & 22 \\
\hline 21 & APP & 25 & 51 & 23 \\
\hline 22 & $\begin{array}{l}\text { Tris(2-hydroxyethyl) isocyanurate polyphosphate } \\
\text { melamine (TPM) }\end{array}$ & 25 & 61 & 23 \\
\hline 23 & APP/TPM & 25 & 68 & 23 \\
\hline 24 & APP & 5 & 38 & 24 \\
\hline 25 & Lignin & 5 & 2 & 24 \\
\hline 26 & APP/Lignin & 20 & 32 & 24 \\
\hline 27 & ATH & 30 & 29 & 25 \\
\hline 28 & ATH/MMT & 30 & 48 & 25 \\
\hline 29 & ATH/MMT & 30 & 55 & 25 \\
\hline 30 & ATH & 40 & 35 & 25 \\
\hline 31 & ATH/MMT & 40 & 60 & 25 \\
\hline 32 & ATH/MMT & 40 & 60 & 25 \\
\hline 33 & ATH & 50 & 50 & 25 \\
\hline 34 & ATH/MMT & 50 & 63 & 25 \\
\hline 35 & ATH/MMT & 50 & 65 & 25 \\
\hline 36 & Functionalized $\alpha$-zirconium phosphate & 5 & 37 & 26 \\
\hline 37 & Functionalized $\alpha$-zirconium phosphate & 10 & 42 & 26 \\
\hline 38 & Functionalized $\alpha$-zirconium phosphate & 20 & 52 & 26 \\
\hline 39 & $\alpha$-zirconium phosphate & 5 & 39 & 26 \\
\hline 40 & $\alpha$-zirconium phosphate & 10 & 44 & 26 \\
\hline 41 & $\alpha$-zirconium phosphate & 20 & 47 & 26 \\
\hline 42 & kraft lignin & 20 & 21 & 5 \\
\hline 43 & Organosolv lignin & 20 & 33 & 5 \\
\hline 44 & Na- Phytate & 20 & 23 & 15 \\
\hline
\end{tabular}




\begin{tabular}{|c|l|c|c|c|}
\hline 45 & Na- Phytate & 30 & 36 & 15 \\
\hline 46 & Al- Phytate & 20 & 44 & 15 \\
\hline 47 & Al- Phytate & 30 & 53 & 15 \\
\hline 48 & Fe- Phytate & 20 & 24 & 15 \\
\hline 49 & La- Phytate & 20 & 35 & 15 \\
\hline 50 & Na- Phytate/Al- Phytate & 20 & 47 & 15 \\
\hline 51 & Na- Phytate/Fe- Phytate & 20 & 47 & 15 \\
\hline 52 & Na- Phytate/La-Phytic acid & 20 & 43 & 15 \\
\hline 53 & Na- Phytate /Al-P Phytate & 20 & 45 & 15 \\
\hline 54 & Na- Phytate/Fe- Phytate & 20 & 36 & 15 \\
\hline 55 & Na- Phytate/La- Phytate & 20 & 36 & 15 \\
\hline 56 & MicroCrystalline Cellulose & 20 & 8 & 8 \\
\hline 57 & NanoCrystalline Cellulose & 20 & 35 & 8 \\
\hline 58 & Al-Phytate & 10 & 10 & 8 \\
\hline 59 & Al-Phytate & 20 & 44 & 8 \\
\hline 60 & Al- Phytate/MicroCrystalline Cellulose & 20 & 15 & 8 \\
\hline 61 & Al- Phytate/NanoCrystalline Cellulose & 20 & 38 & 8 \\
\hline 62 & phosphorylated MicroCrystalline Cellulose & 20 & 15 & 8 \\
\hline \multirow{2}{*}{63} & Al- Phytate/phosphorylated MicroCrystalline & 20 & 33 & 8 \\
& Cellulose & 20 & 38 & 8 \\
\hline \multirow{2}{*}{64} & \begin{tabular}{l} 
Al- Phytate /phosphorylated MicroCrystalline \\
\cline { 2 - 4 } \\
Cellulose
\end{tabular} & & & \multirow{2}{*}{8} \\
\hline
\end{tabular}

Annex 2: collected data from the literature on "Flame retardancy and mass molar of Flame retarded-PLA".

\begin{tabular}{|c|l|c|c|c|}
\hline $\mathbf{N}^{\circ}$ & \multicolumn{1}{|c|}{$\begin{array}{c}\text { Name(s) of Flame retardant(s), incorporated into } \\
\text { PLA }\end{array}$} & $\begin{array}{c}\text { Reduction in } \\
\text { pHRR (\%) }\end{array}$ & $\begin{array}{c}\text { *Reduction } \\
\text { in molar } \\
\text { mass (\%) }\end{array}$ & Ref. \\
\hline 1 & Phytate Na & 23 & 11 & 15 \\
\hline 2 & Phytate Fe & 24 & 51.5 & 15 \\
\hline 3 & Phytate La & 35 & 29 & 15 \\
\hline 4 & Phytate Al & 44 & 76 & 15 \\
\hline 5 & phyt Al/ phyt Na & 47 & 21 & 15 \\
\hline 6 & phyt Fe / phyt Na & 47 & 27 & 15 \\
\hline 7 & phyt La/ phyt Na & 43 & 22.5 & 15 \\
\hline 8 & organosolv lignin & 33 & 82.6 & 5 \\
\hline 9 & kraft lignin & 21 & 57 & 5 \\
\hline 10 & organosolv lignin phosphorus & 33 & 68 & 5 \\
\hline 11 & kraft lignin phosphorus & 40 & 54 & 5 \\
\hline 12 & kraft /phytic & 44 & 40 & 13 \\
\hline 13 & organosolv / phytic & 36 & 25 & 13 \\
\hline
\end{tabular}

*Molar mass of all PLA used in these studies was around $100000 \mathrm{~g} / \mathrm{mol}$. 


\section{Graphical Abstract}

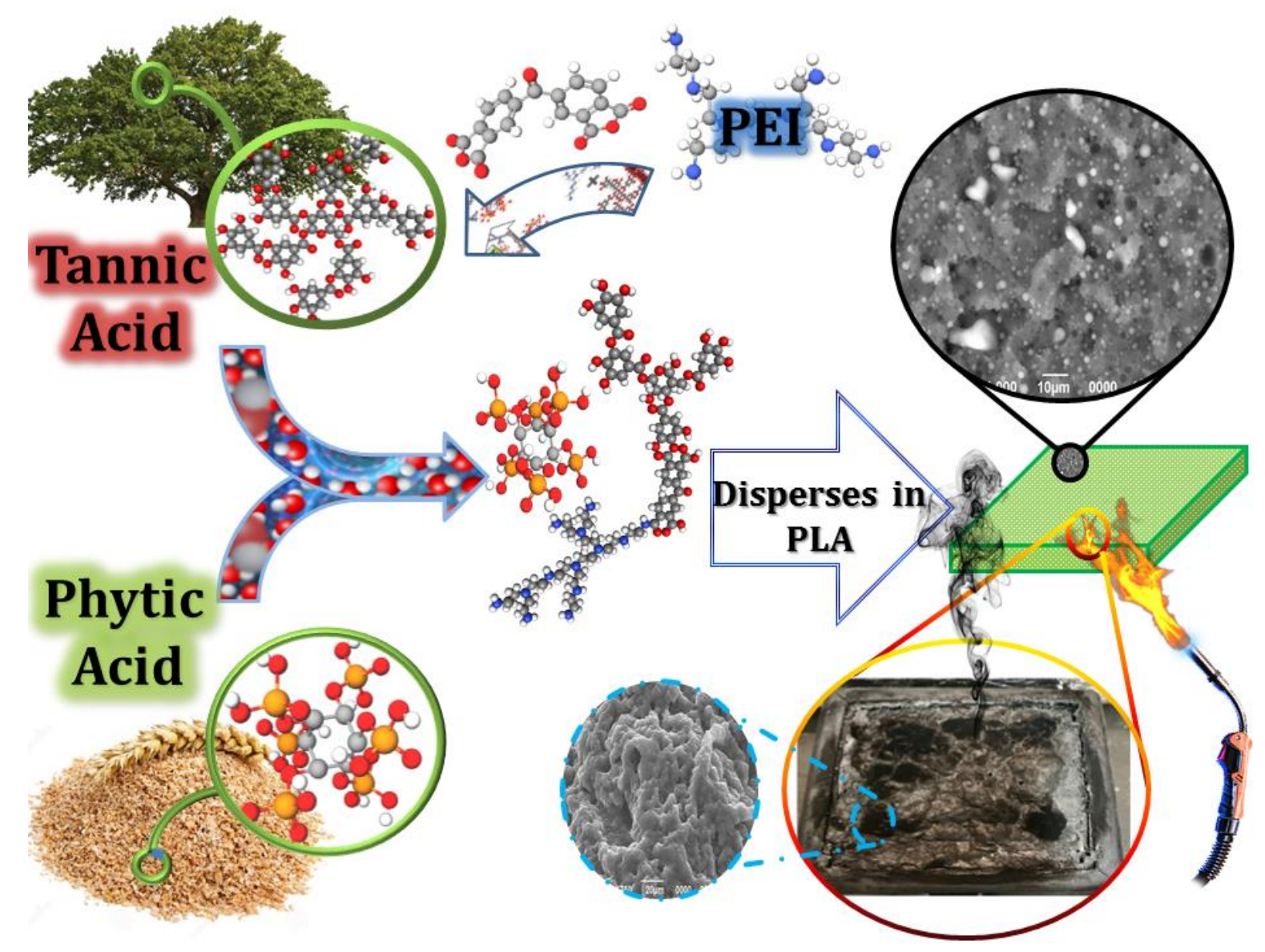

\section{References:}

[1] F. Laoutid, L. Bonnaud, M. Alexandre, J.-M. Lopez-Cuesta, P. Dubois, New prospects in flame retardant polymer materials: from fundamentals to nanocomposites, Materials Science and Engineering: R: Reports 63(3) (2009) 100-125.

[2] S.-Y. Lu, I. Hamerton, Recent developments in the chemistry of halogen-free flame retardant polymers, Prog. Polym. Sci. 27(8) (2002) 1661-1712.

[3] G. Gallina, E. Bravin, C. Badalucco, G. Audisio, M. Armanini, A. De Chirico, F. Provasoli, Application of cone calorimeter for the assessment of class of flame retardants for polypropylene, Fire Mater. 22(1) (1998) 1518.

[4] L. Ferry, G. Dorez, A. Taguet, B. Otazaghine, J. Lopez-Cuesta, Chemical modification of lignin by phosphorus molecules to improve the fire behavior of polybutylene succinate, Polym. Degrad. Stab. 113 (2015) 135-143.

[5] L. Costes, F. Laoutid, M. Aguedo, A. Richel, S. Brohez, C. Delvosalle, P. Dubois, Phosphorus and nitrogen 
derivatization as efficient route for improvement of lignin flame retardant action in PLA, Eur. Polym. J. 84 (2016) 652-667.

[6] K. Wu, Y. Hu, L. Song, H. Lu, Z. Wang, Flame retardancy and thermal degradation of intumescent flame retardant starch-based biodegradable composites, Ind. Eng. Chem. Res. 48(6) (2009) 3150-3157. [7] X. Wang, Y. Hu, L. Song, S. Xuan, W. Xing, Z. Bai, H. Lu, Flame retardancy and thermal degradation of intumescent flame retardant poly(lactic acid)/starch biocomposites, Ind. Eng. Chem. Res. 50(2) (2010) 713-720. [8] L. Costes, F. Laoutid, F. Khelifa, G. Rose, S. Brohez, C. Delvosalle, P. Dubois, Cellulose/phosphorus combinations for sustainable fire retarded polylactide, Eur. Polym. J. 74 (2016) 218-228. [9] D.M. Fox, S. Temburni, M. Novy, L. Flynn, M. Zammarano, Y.S. Kim, J.W. Gilman, R.D. Davis, Thermal and burning properties of poly (lactic acid) composites using cellulose-based intumescing flame retardants, Fire and polymers VI: new advances in flame retardant chemistry and science, ACS Publications2012, pp. 223-234. [10] J. Alongi, M. Pošković, A. Frache, F. Trotta, Novel flame retardants containing cyclodextrin nanosponges and phosphorus compounds to enhance EVA combustion properties, Polym. Degrad. Stab. 95(10) (2010) 2093 2100 .

[11] J. Alongi, M. Poskovic, P. Visakh, A. Frache, G. Malucelli, Cyclodextrin nanosponges as novel green flame retardants for PP, LLDPE and PA6, Carbohydr. Polym. 88(4) (2012) 1387-1394.

[12] F. Laoutid, V. Karaseva, L. Costes, S. Brohez, R.Minchieva, P. Dubois, Novel bio-based flame retardant systems derived from tannic acid, Submitted to Journal of Renewable Materials (2018).

[13] L. Costes, F. Laoutid, S. Brohez, C. Delvosalle, P. Dubois, Phytic acid-lignin combination: A simple and efficient route for enhancing thermal and flame retardant properties of polylactide, Eur. Polym. J. 94 (2017) 270285.

[14] B. Schartel, T. Hull, Development of fire-retarded materials-Interpretation of cone calorimeter data, Fire Mater. 31(5) (2007) 327-354.

[15] L. Costes, F. Laoutid, L. Dumazert, J.-M. Lopez-cuesta, S Brohez, C. Delvosalle, P. Dubois, Metallic phytates as efficient bio-based phosphorous flame retardant additives for poly (lactic acid), Polym. Degrad. Stab. 119 (2015) 217-227.

[16] G. Fontaine, S. Bourbigot, Intumescent polylactide: a nonflammable material, Journal of applied polymer science, 113 (2009) 3860-3865.

[17] C. Reti, M. Casetta, S. Duquesne, S. Bourbigot, R. Delobel, Flammability properties of intumescent PLA including starch and lignin, Polymers for advanced Technologies, 19 (2008) 628-635.

[18] R. Zhang, X. Xiao, Q. Tai, H. Huang, J. Yang, Y. Hu, The effect of different organic modified montmorillonites (OMMTs) on the thermal properties and flammability of PLA/MCAPP/lignin systems, Journal of Applied Polymer Science, 127 (2013) 4967-4973.

[19] N. Lesaffre, S. Bellayer, G. Fontaine, M. Jimenez, S. Bourbigot, Revealing the impact of ageing on a flame retarded PLA, Polym. Degrad. Stab., 127 (2016) 88-97.

[20] R. Zhang, X. Xiao, Q. Tai, H. Huang, Y. Hu, Modification of lignin and its application as char agent in intumescent flame-retardant poly (lactic acid), Polymer Engineering \& Science, 52 (2012) 2620-2626. 
[21] H. Zhu, Q. Zhu, J. Li, K. Tao, L. Xue, Q. Yan, Synergistic effect between expandable graphite and ammonium polyphosphate on flame retarded polylactide, Polym. Degrad. Stab., 96 (2011) 183-189.

[22] D.M. Fox, J. Lee, C.J. Citro, M. Novy, Flame retarded poly (lactic acid) using POSS-modified cellulose. 1. Thermal and combustion properties of intumescing composites, Polym. Degrad. Stab., 98 (2013) 590-596.

[23] X. Zhao, S. Gao, G. Liu, A THEIC-based polyphosphate melamine intumescent flame retardant and its flame retardancy properties for polylactide, Journal of Analytical and Applied Pyrolysis, 122 (2016) 24-34.

[24] S. Bourbigot, G. Fontaine, Flame retardancy of polylactide: an overview, Polymer Chemistry, 1 (2010) 1413-1422.

[25] K.-C. Cheng, C.-B. Yu, W. Guo, S.-F. Wang, T.-H. Chuang, Y.-H. Lin, Thermal properties and flammability of polylactide nanocomposites with aluminum trihydrate and organoclay, Carbohydrate polymers, 87 (2012) 1119-1123.

[26] X.-Q. Liu, D.-Y. Wang, X.-L. Wang, L. Chen, Y.-Z. Wang, Synthesis of functionalized $\alpha$-zirconium phosphate modified with intumescent flame retardant and its application in poly (lactic acid), Polym. Degrad. Stab., 98 (2013) 1731-1737. 